ARTICLE

\title{
Oxygen-rich interface enables reversible stibium stripping/plating chemistry in aqueous alkaline batteries
}

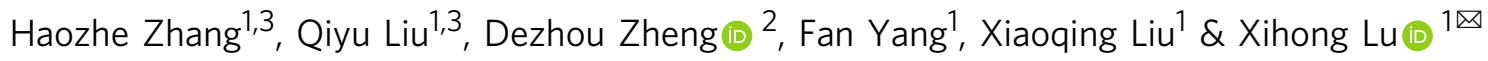

Aqueous alkaline batteries see bright future in renewable energy storage and utilization, but their practical application is greatly challenged by the unsatisfactory performance of anode materials. Herein, we demonstrate a latent Sb stripping/plating chemistry by constructing an oxygen-rich interface on carbon substrate, thus providing a decent anode candidate. The functional interface effectively lowers the nucleation overpotential of $\mathrm{Sb}$ and strengthens the absorption capability of the charge carriers $\left(\mathrm{SbO}_{2}{ }^{-}\right.$ions). These two advantageous properties inhibit the occurrence of side reactions and thus enable highly reversible $\mathrm{Sb}$ stripping/plating. Consequently, the Sb anode delivers theoretical-value-close specific capacity $\left(627.1 \mathrm{~mA} \mathrm{~h} \mathrm{~g}^{-1}\right)$, high depth of discharge (95.0\%) and maintains $92.4 \%$ coulombic efficiency over 1000 cycles. A robust aqueous $\mathrm{NiCO}_{2} \mathrm{O}_{4} / / \mathrm{Sb}$ device with high energy density and prominent durability is also demonstrated. This work provides a train of thoughts for the development of aqueous alkaline batteries based on Sb chemistry.

\footnotetext{
${ }^{1} \mathrm{MOE}$ of the Key Laboratory of Bioinorganic and Synthetic Chemistry, The Key Lab of Low-carbon Chem \& Energy Conservation of Guangdong Province, School of Chemistry, Sun Yat-Sen University, 510275 Guangzhou, People's Republic of China. ${ }^{2}$ School of Applied Physics and Materials, Wuyi University, 529020 Jiangmen, People's Republic of China. ${ }^{3}$ These authors contributed equally: Haozhe Zhang, Qiyu Liu. ${ }^{\circledR}$ email: luxh6@mail.sysu.edu.cn
} 


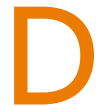

emanding requirements for renewable energy storage/ utilization greatly stimulate the boom of economical, safe, and efficient batteries ${ }^{1-5}$. With the ever-growing energy consumption, the levelized energy cost (LEC), the economic cost per $\mathrm{kW} \mathrm{h}$ delivered as output over the entire lifespan of the devices, has becoming the most important indicator of the batteries $^{6-9}$. Therefore, to evaluate the overall performance of the energy storage devices, several parameters need to be taken into account together, including the initial capital cost, specific energy, and cycling ability. Along this line, rechargeable aqueous alkaline batteries (AABs), the devices that realize energy storage via the faradaic reactions of electrodes in alkaline electrolyte, emerge as one of the most promising next-generation candidates for renewable energy storage, especially for large-scale applications ${ }^{10,11}$. This should be ascribed to the advantageous properties of aqueous electrolytes including high ionic conductivity $\left(\sim 1 \mathrm{~S} \mathrm{~cm}^{-1}\right)$, low cost, and intrinsic nonflammability ${ }^{12}$. Over the past years, tremendous research attention has been paid to the exploration of various electrode materials for AABs, and significant achievements have been gained in this field ${ }^{13-16}$. Compared with the booming cathode materials, the choice of anode materials remains quite limited and their development is relatively slow.

Currently, based on the disparate differences of their energy storage behavior, the reported anodes are mainly classified into two categories: conversion-type ones and stripping/plating-type ones. Conversion-type anodes such as $\mathrm{Cd}^{17}, \mathrm{Bi}^{18,19}$, and $\mathrm{FeO}_{\mathrm{x}}{ }^{20,21}$ experience phase conversion (usually from metal/metal oxide to their corresponding metal oxide/hydroxide) during the charging-discharging process. Yet, the intrinsically poor conductivity and slow reaction kinetics of the metal oxides/hydroxides lead to low capacity and limited rate capability. In contrast, $\mathrm{Zn}$ anodes, the most representative stripping/plating-type electrodes, are not bothered by such troubles because they rely on the transformation of metal/metal ions for energy storage, which ensures fast reaction kinetics ${ }^{22-24}$. Unfortunately, due to the uncontrollable dendrite growth of $\mathrm{Zn}$ and the accompanying side reactions, this metal anode suffers from inferior cycling stability and low coulombic efficiency (CE), seriously impeding its further development ${ }^{25}$. Therefore, it is of great significance to explore novel anode materials embedding both high energy and favorable stability to facilitate the practical applications of AABs in renewable energy storage/utilization, which remains a great challenge in this area.

Stibium ( $\mathrm{Sb}$ ) metal is a desirable anode material owing to its high theoretic capacity $\left(660 \mathrm{~mA} \mathrm{~h}^{-1}\right.$, based on three-electron transfer reaction), favorable negative redox potential in alkaline solution $(-0.66 \mathrm{~V}$ vs. the standard hydrogen electrode) and low cost $(\sim 7 \$ \text { per } \mathrm{kg})^{26,27}$. Furthermore, according to the $\varphi-\mathrm{pH}$ diagram for $\mathrm{H}_{2} \mathrm{O}-\mathrm{Sb}$ and previous studies, the $\mathrm{Sb}$ (III) will exist as soluble $\mathrm{SbO}_{2}{ }^{-}$rather than $\mathrm{Sb}_{2} \mathrm{O}_{3}$ precipitate in aqueous alkaline environment, which endows $\mathrm{Sb}$ metal the capability to function more like the stripping/plating-type anodes with fast kinetics in $\mathrm{AABs}^{28-31}$. To our knowledge, there is hardly any report on the employment of metallic $\mathrm{Sb}$ as electrode in aqueous systems, let alone in AABs. For a Sb-based AAB device, there exists strong electrostatic repulsion force between the charge carriers $\left(\mathrm{SbO}_{2}{ }^{-}\right)$ and the electrode surface, both negatively charged during the plating courses. Such specific interaction makes it difficult for $\mathrm{SbO}_{2}{ }^{-}$ions to approach the anode for proper deposition, and might initiate severe side reactions such as hydrogen evolution. Hence, the key challenge lies in how to manipulate precisely the behaviors of $\mathrm{SbO}_{2}^{-}$ions at the interface.

Herein, by constructing a functional oxygen-rich interface, we realize highly reversible stripping/plating chemistry of $\mathrm{Sb}$ metal anode on the carbon substrate (denoted as CS) in AABs. Oxygen- containing functional groups facilitate the diffusion and deposition behaviors of $\mathrm{SbO}_{2}{ }^{-}$ions on the carbon surface via two ways: (i) to promote the absorption of the $\mathrm{SbO}_{2}{ }^{-}$at the interface by activating the formation of hydrogen bonds; (ii) to decrease the deposition resistance of $\mathrm{Sb}$ by minimizing the nucleation overpotential on the anode. Benefiting from these two merits, the potential side reactions are substantially inhibited and highly reversible deposition/dissolution of $\mathrm{Sb}$ is realized on the functionalized carbon substrate (denoted as FCS). As a result, the $\mathrm{Sb} /$ FCS anode delivers a high specific capacity of $627.1 \mathrm{~mA} \mathrm{~h} \mathrm{~g}^{-1}$ ( $95.0 \%$ depth of discharge, DOD), along with admirable CE $(\sim 95.9 \%)$ and satisfactory cycling durability (92.4\% CE after 1000 cycles). When coupled with a phosphating $\mathrm{NiCo}_{2} \mathrm{O}_{4}$ (denoted as $\mathrm{P}-\mathrm{NiCo}_{2} \mathrm{O}_{4}$ ) cathode, the electrochemical performance of the $\mathrm{AAB}$ device outperforms most recently reported AABs, as testified by its superior energy density $\left(8.2 \mathrm{~mW} \mathrm{~h} \mathrm{~cm}^{-3}\right)$, excellent power density $\left(0.4 \mathrm{~W} \mathrm{~cm}^{-3}\right)$, as well as its admirable stability ( $98.1 \%$ capacity retention over 1000 cycles). This work opens a favorable way for the exploration of novel Sb-based aqueous devices as power supply systems.

\section{Results}

Stripping/plating chemistry studies of stibium. The stripping/ plating chemistry of $\mathrm{Sb}$ on different substrates is compared in Fig. 1a. Because the $\mathrm{Sb}$ (III) will exist as $\mathrm{SbO}_{2}{ }^{-}$without forming tartrate- $\mathrm{Sb}$ complex in potassium antimony tartrate- $\mathrm{KOH}$ aqueous system, the simplified schematic illustration only shows the $\mathrm{K}^{+}$and $\mathrm{SbO}_{2}{ }^{-}$for demonstration ${ }^{28}$. For the CS substrate, at the very beginning, the disordered molecular thermodynamic motion of the $\mathrm{SbO}_{2}-$ ions leads to their random distribution in the electrolyte. Upon charging the anode, the $\mathrm{SbO}_{2}{ }^{-}$ions in the Helmholtz layer are reduced to $\mathrm{Sb}$ on the substrate, and the as-deposited $\mathrm{Sb}$ metal would resolve into the electrolyte during the discharging course. It is noteworthy that, in the charging process, a large portion of $\mathrm{SbO}_{2}{ }^{-}$ ions would migrate toward the counter electrode instead of the deposition substrate, leading to catastrophic plating efficiency or even side reactions. This should be attributed to the strong electrostatic repulsion between the charge carriers $\left(\mathrm{SbO}_{2}{ }^{-}\right)$and the negatively-charged CS surface. Therefore, to enable highly reversible stripping/plating chemistry of $\mathrm{Sb}$, it is essential to design a functionalized carbon interface that is capable of "capturing" tightly the $\mathrm{SbO}_{2}{ }^{-}$in the close vicinity of the electrode at the deposition stage. To achieve this goal, we decorate the CS with some oxygencontaining functional groups via a facile electrochemical activation strategy. As shown in Supplementary Fig. 1, the untreated CS consisting of interlaced carbon fibers exhibits a smooth surface and it becomes relatively rough after electrochemical treatment. The Brunauer-Emmett-Teller surface areas of both samples shown in Supplementary Fig. 2 remain small values, but which of FCS becomes slightly larger after the treatment (from 1.4 to $3.2 \mathrm{~m}^{2} \mathrm{~g}^{-1}$ ). The introduction of oxygen functional groups in FCS is accompanied by the generation of graphene edges with thickness of about $10 \mathrm{~nm}$ (Supplementary Fig. 3). In addition, the X-ray diffraction (XRD) spectra of CS and FCS (Supplementary Fig. 4) are both perfectly indexed to hexagonal graphite (JCPDF\#41-1487), indicating their similar crystalline structure ${ }^{32}$. Yet, the detailed X-ray photoelectron spectroscopy (XPS) analysis of the C $1 s$ peak reveals that the electrochemical activation process successfully introduces oxygen atoms to the FCS surface in the form of $\mathrm{C}-\mathrm{OH}(285.7 \mathrm{eV})$, $\mathrm{C}=\mathrm{O}(286.9 \mathrm{eV})$, and $\mathrm{O}-\mathrm{C}=\mathrm{O}(288.7 \mathrm{eV})(\text { Supplementary Fig. } 5)^{33}$. Congruously, the intensity of $\mathrm{O} 1 \mathrm{~s}$ peak for the FCS $(\mathrm{O} / \mathrm{C}$ ratio $=$ $0.17)$ is also much higher than the $\mathrm{CS}(\mathrm{O} / \mathrm{C}$ ratio $=0.04)$. Electrochemical impedance spectra (EIS) in Supplementary Fig. 6 indicates that the charge transfer resistance of FCS is slightly increased, consistent with the previous work ${ }^{32}$. Nevertheless, the 
oxygen-rich interface holds great potential for boosting the $\mathrm{Sb}$ deposition because it can provide abundant receptors and donors for the formation of hydrogen bonds that favors the adsorption of $\mathrm{SbO}_{2}{ }^{-}$ions in the Helmholtz layer.

The working potential window of the CS and FCS electrodes in $1 \mathrm{M} \mathrm{KOH}$ with $0.027 \mathrm{M} \mathrm{C}_{8} \mathrm{H}_{4} \mathrm{~K}_{2} \mathrm{O}_{12} \mathrm{Sb}_{2}$ was tested by linear sweep voltammetry (LSV) at $1 \mathrm{mV} \mathrm{s}^{-1}$. As shown in Supplementary Fig. 7, the $\mathrm{H}_{2}$ evolution reactions on both two electrodes take place at around $-1.5 \mathrm{~V}$, so the potential window of 0 to $-1.3 \mathrm{~V}$ was selected to avoid water splitting. Cyclic voltammograms $(\mathrm{CV})$ within this voltage window were recorded on the CS and FCS at 2 and $10 \mathrm{mV} \mathrm{s}^{-1}$ to study the stripping/plating chemistry of Sb (Supplementary Fig. 8). Both electrodes possess one redox couple whereas smaller voltage polarization is visualized on the FCS sample, indicating its higher reversibility. Further chemical composition investigation verifies the redox couple corresponds to the deposition/dissolution of Sb (Fig. 1b-g and Supplementary Fig. 9). Specifically, when the charging capacity is set to $0.47 \mathrm{~mA} \mathrm{~h} \mathrm{~cm}^{-2}$, the precipitates on both electrodes are confirmed to be pure hexagonal $R-3 \mathrm{~m}$ phase $\mathrm{Sb}$ without other impurities (JCPDS\#85-1322, Supplementary Fig. 10 $)^{34,35}$. The high-resolution transmission electron microscopy (HRTEM) characterization in Supplementary Fig. 11 further testifies this viewpoint. The lattice spacing of $0.31 \mathrm{~nm}$ matches well with the (012) plane of hexagonal Sb (JCPDS\#851322), while the bright diffraction and highly-ordered spots in the selected-area electron diffraction (SAED) patterns indicate its good crystallinity ${ }^{36}$. When the electrodes are discharged to $0 \mathrm{~V}$ (discharging state), Sb metal are nearly completely dissolved back to the electrolyte. Notably, in the charging stage, the Sb metal (Fig. 1d) deposits as randomly-distributed, isolated nanoflowers, leaving some uncovered spaces on the CS. In contrast, the deposition of $\mathrm{Sb}$ seems more homogeneous on the entire surface of the FCS (Fig. 1e), indicative of the superiority of the oxygendecorated functional interface. The $\mathrm{Sb} / \mathrm{SbO}_{2}{ }^{-}$transformation during the charging/discharging is also verified by the ex situ
XRD spectra (Supplementary Fig. 12), in which the characteristic peaks of metallic Sb disappear at the discharging state and recover at the charging state.

To highlight the superiority of the FCS over the CS, their electrochemical behaviors are compared with a fixed charging capacity of $0.47 \mathrm{~mA} \mathrm{~h} \mathrm{~cm}^{-2}$. At a current density of $30 \mathrm{~mA} \mathrm{~cm}^{-2}$, the charge limited voltage $\left(V_{\mathrm{cl}}\right)$ of $\mathrm{Sb} / \mathrm{CS}$, which means the voltage attained at the end of charging (absolute value), reaches a high value of $1.50 \mathrm{~V}$ within merely 50 cycles and increases to $1.70 \mathrm{~V}$ after 500 cycles, accompanied by severe hydrogen evolution (Supplementary Fig. 13). The Sb/FCS electrode shows a stable charging voltage profile, along with a low $V_{\mathrm{cl}}$ about $1.25 \mathrm{~V}$ for 1000 cycles (Fig. 2a). At a smaller current density of $20 \mathrm{~mA} \mathrm{~cm}^{-2}$ (Fig. 2b), the hydrogen evolution of the Sb/CS electrode is intensified, resulting in a high $V_{\mathrm{cl}}$ of $1.55 \mathrm{~V}$ after only ten cycles. In contrast, the $V_{\mathrm{cl}}$ of the Sb/FCS electrode is only $1.30 \mathrm{~V}$ after 1000 cycles (Supplementary Fig. 14), signifying its better cycling durability. Moreover, it should be noticed that the test duration of $\mathrm{Sb} / \mathrm{FCS}$ at both current densities lasts much longer than Sb/CS. The charging time and cycling numbers of $\mathrm{Sb} / \mathrm{CS}$ and $\mathrm{Sb} / \mathrm{FCS}$ are the same, so the longer test time means longer average discharging time, manifesting longer average discharging time and better $\mathrm{CE}$ of $\mathrm{Sb} / \mathrm{FCS}$.

According to the discharging curves at $20 \mathrm{~mA} \mathrm{~cm}^{-2}$ in Fig. $2 \mathrm{c}$, the $\mathrm{Sb} / \mathrm{CS}$ show a capacity of $\sim 0.32 \mathrm{~mA} \mathrm{~h} \mathrm{~cm}^{-2}$ at the first 50 cycles. When the cycling test is extended from 100 to 1000 cycles, it fades rapidly from 0.18 to $0.05 \mathrm{~mA} \mathrm{~h} \mathrm{~cm}^{-2}$, signifying the irreversible plating/stripping courses. Obviously, the Sb/FCS maintains a much larger discharging capacity in the range of $0.42-0.45 \mathrm{~mA} \mathrm{~h} \mathrm{~cm}^{-2}$ during the 1000 cycles. At lower current density conditions $\left(2-8 \mathrm{~mA} \mathrm{~cm}^{-2}\right)$, the discharging capacities of $\mathrm{Sb} / \mathrm{FCS}$ can even achieve more than $0.46 \mathrm{~mA} \mathrm{~h} \mathrm{~cm}^{-2}$ (Supplementary Fig. 15). It is worth noting that the capacitive charge contribution of both CS and FCS only account for ignorable percentage comparing with the discharging capacity of $\mathrm{Sb} / \mathrm{CS}$ $(\sim 1.3 \%)$ and $\mathrm{Sb} / \mathrm{FCS}(\sim 2.8 \%)$, indicating the capacities are mainly

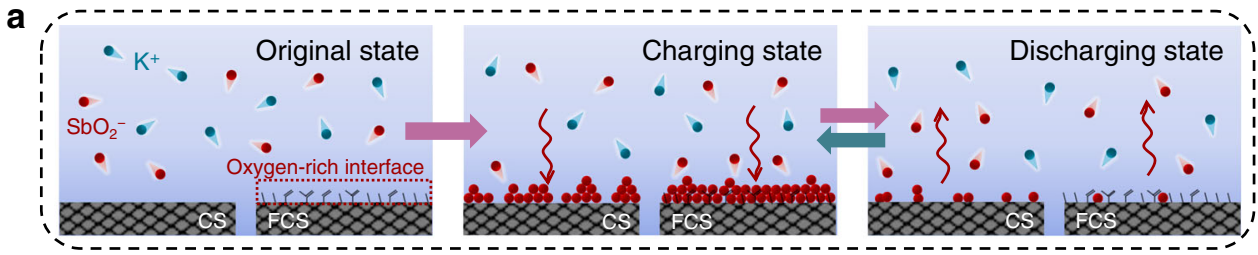

b

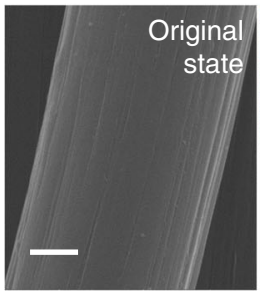

C

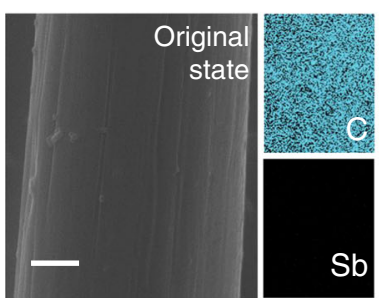

d

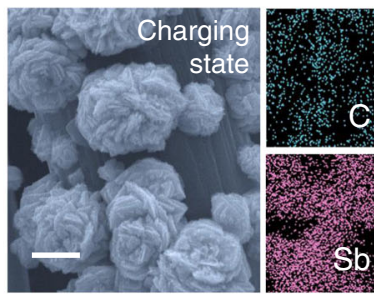

e

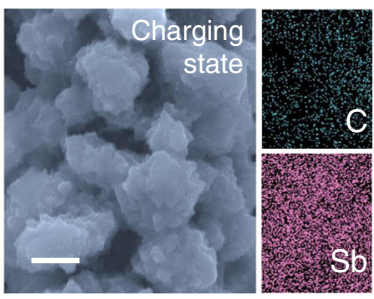

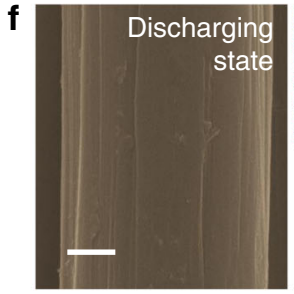

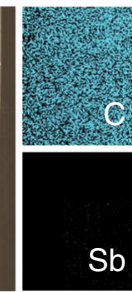

9
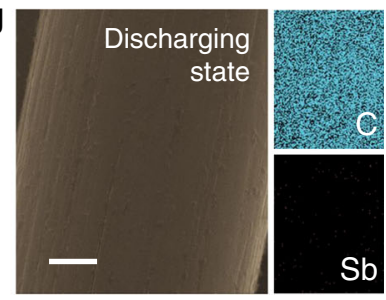

Fig. 1 Charge storage mechanism investigations of stibium. a Schematic illustration of the charge storage mechanism of the $\mathrm{Sb}$ anode in $1 \mathrm{M} \mathrm{KOH}$ and

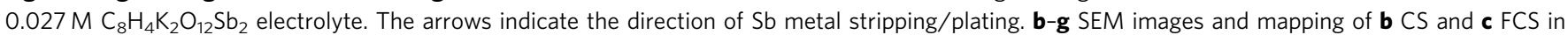
original state; $\mathbf{d} \mathrm{Sb} / \mathrm{CS}$ and e Sb/FCS in charging state; $\mathbf{f} \mathrm{Sb} / \mathrm{CS}$ and $\mathbf{g} \mathrm{Sb} / \mathrm{FCS}$ in discharging state. Scale bars: $2 \mu \mathrm{m}$. 

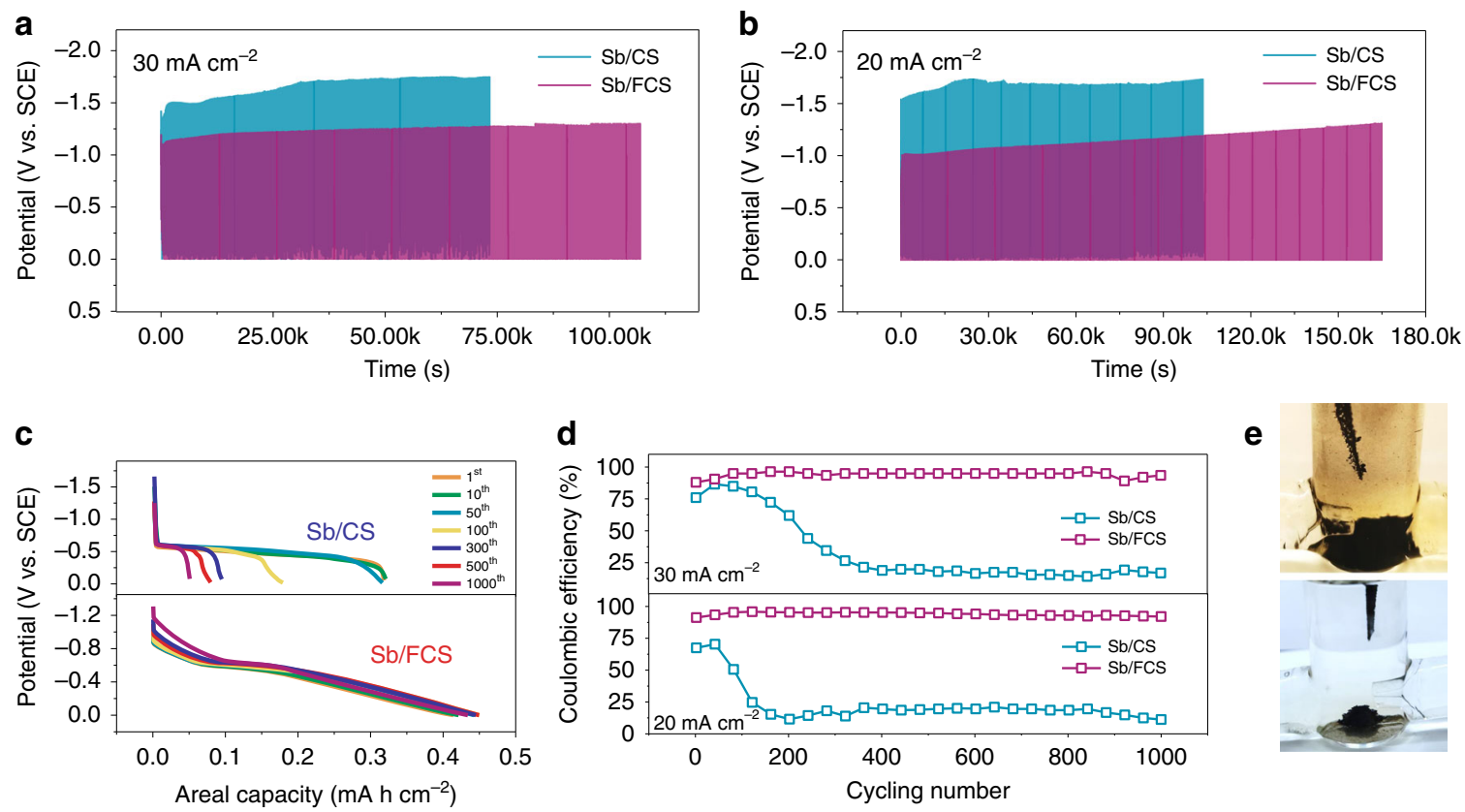

Fig. 2 Electrochemical characterizations of Sb/CS and Sb/FCS electrodes. Voltage profiles of Sb/CS and Sb/FCS with a fixed charging capacity of $0.47 \mathrm{~mA} \mathrm{~h} \mathrm{~cm}^{-2}$ at $\mathbf{a} 30 \mathrm{~mA} \mathrm{~cm}^{-2}$ ( $55 \mathrm{~s}$ charging) and $\mathbf{b} 20 \mathrm{~mA} \mathrm{~cm}^{-2}$ ( $85 \mathrm{~s}$ charging). c Corresponding discharging curves at different cycles at $20 \mathrm{~mA} \mathrm{~cm}{ }^{-2}$ and $\mathbf{d}$ CE of the Sb stripping/plating on the bare CS and FCS. e Optical photographs of Sb/CS and Sb/FCS after 1000 cycles at $20 \mathrm{~mA} \mathrm{~cm}-2$.

come from the stripping/plating process of $\mathrm{Sb}$ (Supplementary Fig. 16). Additionally, an impressive DOD of $95 \%$ and a superb specific capacity of $627.1 \mathrm{~mA} \mathrm{~h}^{-1}$ are achieved by the Sb/FCS anode (based on the mass loading of $\mathrm{Sb}$ ), outstripping various anodes of aqueous batteries. Besides, the $\mathrm{CE}$ (the ratio of $\mathrm{Sb}$ stripping capacity to Sb plating capacity) of the two samples are also presented in Fig. $2 \mathrm{~d}$ to elucidate the sustainability of the electrodes. As expected, at 20 or $30 \mathrm{~mA} \mathrm{~cm}^{-2}$, the CE of FCS electrode remains to be $92-95 \%$ without attenuation after 1000 cycles. In comparison, the $\mathrm{CE}$ of the CS electrode drops to less than $20 \%$ very shortly at both current densities. Such disappointed performance might be caused by the occurrence of severe side reactions. The morphology characterization of the electrodes after cycling tests shows that the deposition/dissolution processes of $\mathrm{Sb}$ on the $\mathrm{CS}$ are irreversible, leaving much more black sediments (insoluble "dead Sb") (Fig. 2e) ${ }^{37}$. Yet, no obvious difference is seen on the FCS before and after the stability test (Supplementary Fig. 17). It is thus comprehensively demonstrated that the oxygen-rich interface of FCS could restrict the side reactions and guide the reversible stripping/plating chemistry of $\mathrm{Sb}$.

Insights into reversible stripping/plating process. The role of the oxygen-rich interface of FCS in inducing reversible Sb stripping/plating chemistry was then investigated theoretically by density functional theory (DFT) calculations. During the plating process, the absorption properties of $\mathrm{SbO}_{2}{ }^{-}$on the substrate surface have a vital effect on the $\mathrm{Sb} / \mathrm{SbO}_{2}{ }^{-}$conversion reaction. Figure $3 \mathrm{a}$ describes the absorption energy of the $\mathrm{SbO}_{2}{ }^{-}$for the CS surface with or without the introduction of the oxygen-containing functional groups. Remarkably, the surfaces with all kinds of functional groups including $>\mathrm{C}=\mathrm{O}(-2.0 \mathrm{eV}),>\mathrm{C}-\mathrm{OH}(-1.6 \mathrm{eV})$ and $-\mathrm{COOH}(-2.1 \mathrm{eV})$ possess much lower absorption energy than that of the bare CS $(-0.9 \mathrm{eV})$. Therefore, the FCS surface is very likely to gather more $\mathrm{SbO}_{2}{ }^{-}$ions in the Helmholtz layer, which would significantly enhance the Sb plating efficiency. As a proof of concept, when fixing the charging capacity at $0.47 \mathrm{~mA} \mathrm{~h}$ $\mathrm{cm}^{-2}$, the electrochemical reactions on CS can be divided into two stages (Fig. 3b): (i) at around $-1.0 \mathrm{~V}$, an efficient $\mathrm{Sb}$ deposition accounts for $0.17 \mathrm{~mA} \mathrm{hm}^{-2}$; (ii) with the rapid potential increase to $-1.6 \mathrm{~V}$, the hydrogen evolution side reaction (HER) makes up the rest capacity of $0.30 \mathrm{~mA} \mathrm{~h} \mathrm{~cm}^{-2}$. This point can be further proved by the weight variation of CS electrode during the charging process (Supplementary Fig. 18). As illustrated in Fig. 3c, d, when the CS is negatively charged for $\mathrm{Sb}$ plating, the strong electrostatic repulsion force repels the $\mathrm{SbO}_{2}{ }^{-}$ ions to diffuse away from the anode surface. When the few $\mathrm{SbO}_{2}-$ ions left in the Helmholtz layer is completely consumed by initial $\mathrm{Sb}$ deposition, water decomposition reaction will be launched alternatively due to the lack of Sb source, leading to serious hydrogen evolution and active material shedding. Benefitting from the oxygen-rich functional interface, the supplementary of $\mathrm{SbO}_{2}{ }^{-}$in the Helmholtz layer would be substantially more effective on the FCS during the plating. Under this circumstance, the FCS enables an efficient $\mathrm{Sb}$ deposition up to $0.47 \mathrm{~mA} \mathrm{~h} \mathrm{~cm}^{-2}$ at a low cut-off charge voltage of $-1.0 \mathrm{~V}$ (Fig. $3 \mathrm{~b}$ ), getting rid of the interference of HER and thus achieving a high CE. This is highly consistent with the XPS C $1 s$ spectra at the charging state in Supplementary Fig. 19, in which the Sb/FCS holds a raised quantity of $\mathrm{C}-\mathrm{Sb}$ bonds $(\mathrm{C}-\mathrm{Sb}$ : $\mathrm{C}-\mathrm{C}=0.61-0.27)$ compares with the $\mathrm{Sb} / \mathrm{CS}^{38}$. Moreover, the deposition of Sb on FCS can be devided into two stages: (i) 0 to $-0.95 \mathrm{~V}$ and (ii) -0.95 to $-1.0 \mathrm{~V}$. As revealed by the weight variation curve and ex situ scanning electron microscopy (SEM) images of the charging process in Supplementary Fig. 20, the electrochemical deposition of Sb take place on FCS at both stages. The first stage ( 0 to $-0.95 \mathrm{~V})$ might be attributed in an underpotential deposition (UPD)-like process, while the other stage $(-0.95$ to $-1.0 \mathrm{~V})$ is normal deposition process. The nucleation stage is a pivotal step for fully understanding the deposition behaviors of $\mathrm{Sb}$ on different substrates ${ }^{39}$. We then compare the nucleation overpotential disparities of CS and FCS to illuminate the role of oxygen-rich functional interface in modulating $\mathrm{Sb}$ nucleation. The nucleation overpotential is defined as the voltage difference between the lowest voltage, when sharp voltage drops take place and equilibrium potential in the galvanostatic cathodic polarization. As shown in Supplementary 
a

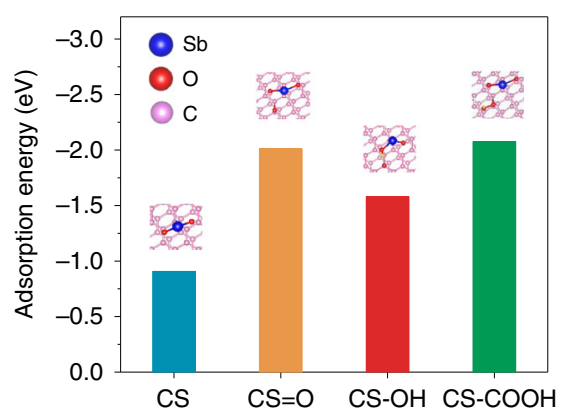

b

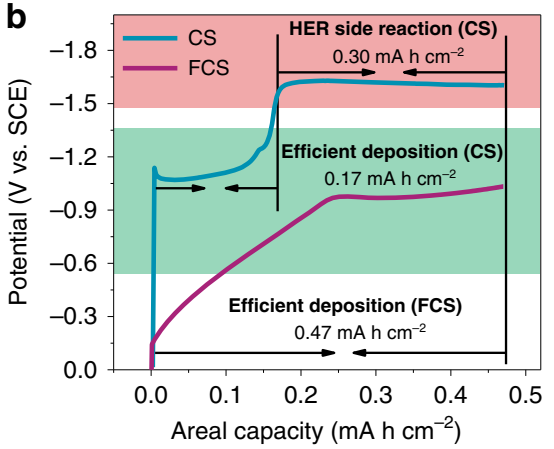

C

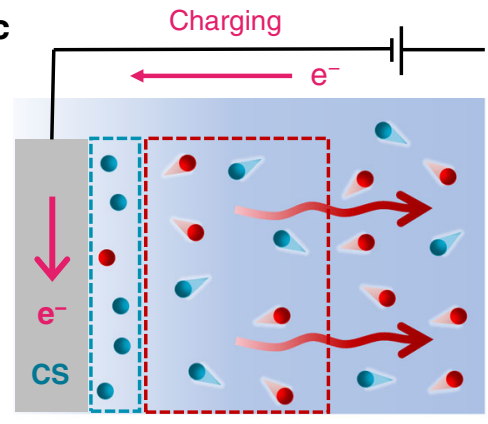

- $\mathrm{SbO}_{2}^{-} \bullet \mathrm{K}^{+} \mathrm{I}_{--}^{--}$Helmholtz layer

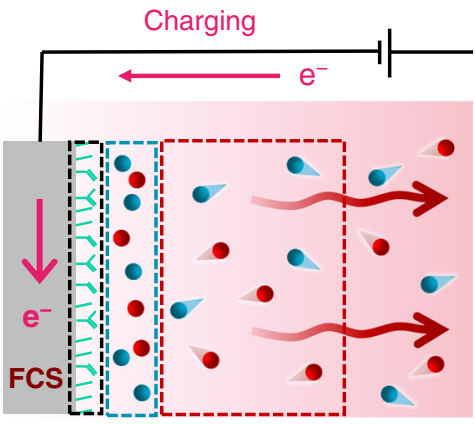

Diffuse layer :-- Oxygen-rich interface

d
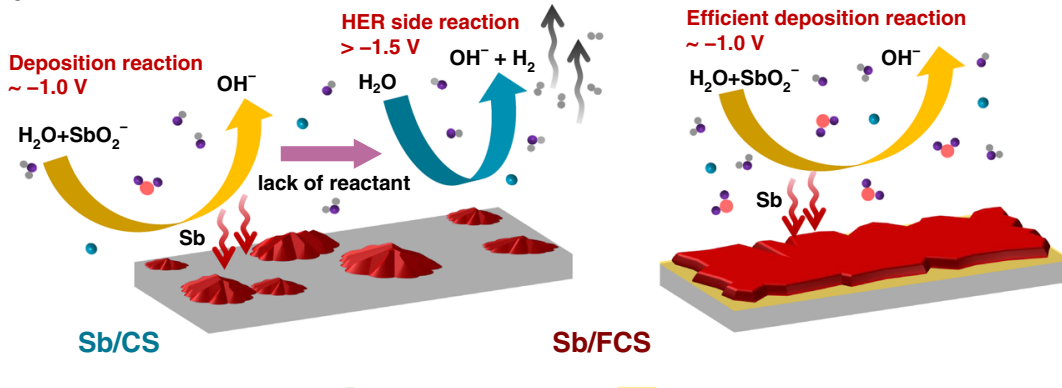

- $\mathrm{K} \odot \mathrm{Sb} \bullet \mathrm{O}-\mathrm{H} \quad$ Functional interface

Fig. 3 Comprehension of oxygen-rich interface induced reversible stripping/plating process. a Relative $\mathrm{SbO}_{2}{ }^{-}$absorption energy profiles of the $\mathrm{CS}$ surface with different functional groups. b Electroplating curve of the Sb on the substrates at $20 \mathrm{~mA} \mathrm{~cm}^{-2}$ with a fixed charging capacity of $0.47 \mathrm{~mA} \mathrm{~h} \mathrm{~cm}^{-2}$. c Illustration of the ion distribution during the plating process of CS and FCS. The arrows indicate the direction of $\mathrm{SbO}_{2}{ }^{-}$diffusion. $\mathbf{d}$ The plating mechanism on the substrate with/without the functional interface induced.

Fig. 21, with respect to the CS, the profile of FCS delivers a smoother voltage dip and a much lower nucleation overpotential (from 147 to $29 \mathrm{mV}$ ), suggesting the oxygen-rich functional interface can dramatically lower the resistance for $\mathrm{Sb}$ nucleation and is more favorable for Sb deposition. Briefly, the FCS integrates the strong absorption capability of the $\mathrm{SbO}_{2}{ }^{-}$and the lower Sb nucleation overpotential, which conjointly contribute to the suppression of side reactions and the high efficiency of $\mathrm{Sb}$ stripping/plating.

Process performance of $\mathrm{NiCo} / / \mathrm{Sb}$ aqueous alkaline battery. In order to further demonstrate the potential of Sb/FCS electrode in energy storage applications, we assembled an AAB device (denote as $\mathrm{NiCo} / / \mathrm{Sb}$ battery) by employing Sb/FCS as anode and $\mathrm{P}-\mathrm{NiCo}_{2} \mathrm{O}_{4}$ (see details in Supplementary Fig. 22 and see "Methods" section) as cathode ${ }^{40}$. Figure 4 a shows the CV curves of the cathode and the anode at $10 \mathrm{mV} \mathrm{s}^{-1}$. The large potential difference between the two electrodes brings about a high discharging platform of $\sim 1.0 \mathrm{~V}$, which is consistent with the $\mathrm{CV}$ results of $\mathrm{NiCo} / / \mathrm{Sb}$ battery (Supplementary Fig. 23). The energy storage mechanism of the $\mathrm{NiCo} / / \mathrm{Sb}$ battery is illustrated in Fig. $4 \mathrm{~b}$, in which the cathode proceeds redox reactions while the anode undergoes stripping/plating process (Supplementary Note 1$)^{22,31,41}$.

It is noteworthy that the as-fabricated battery delivers a large areal capacity of $0.75 \mathrm{~mA} \mathrm{~h} \mathrm{~cm} \mathrm{~cm}^{-2}$ at $8 \mathrm{~mA} \mathrm{~cm}^{-2}$ (Fig. 4c). With the increase of the current density to an ultrahigh level of $36 \mathrm{~mA} \mathrm{~cm}^{-2}$, $0.21 \mathrm{~mA} \mathrm{~h} \mathrm{~cm}^{-2}$ capacity is still retained with only $21 \mathrm{~s}$ discharging, reflecting its good rate ability. When the active material mass of both electrodes is counted, the $\mathrm{NiCo} / / \mathrm{Sb} \mathrm{AAB}$ also reaches a high specific capacity of $175.6 \mathrm{~mA} \mathrm{~h} \mathrm{~g}^{-1}$, superior to recently reported AABs shown in Fig. $4 \mathrm{~d}^{19-21,42,43}$. Furthermore, a maximum volumetric energy density of $8.2 \mathrm{~mW} \mathrm{~h} \mathrm{~cm}^{-3}$ and a maximum volumetric power density of $0.4 \mathrm{~W} \mathrm{~cm}^{-3}$ have been achieved of the battery (based on combined volume of cathode and anode), which considerably surpass a series of $\mathrm{AABs}\left(\right.$ Fig. 4e), like $\mathrm{Ni}-\mathrm{NiO} / / \mathrm{BiO}_{\mathrm{x}}$ battery $\left(1.6 \mathrm{~mW} \mathrm{~h} \mathrm{~cm} \mathrm{~cm}^{-3}, 0.44 \mathrm{~W} \mathrm{~cm}^{-3}\right)^{18}, \mathrm{NiCo}_{2} \mathrm{O}_{4} / / \mathrm{Bi}$ battery $\left(1.5 \mathrm{~mW} \mathrm{~h} \mathrm{~cm}^{-3}, 0.02 \mathrm{~W} \mathrm{~cm}^{-3}\right)^{19}$, NCHO (nickel cobalt hydroxide)//Zn battery $\left(2.2 \mathrm{~mW} \mathrm{~h} \mathrm{~cm}^{-3}, 0.05 \mathrm{~W} \mathrm{~cm}^{-3}\right)^{44}, \mathrm{Ni}(\mathrm{OH})_{2} / /$ $\mathrm{FeO}_{\mathrm{x}}$ battery $\left(2.5 \mathrm{~mW} \mathrm{~h} \mathrm{~cm}^{-3}, 0.03 \mathrm{~W} \mathrm{~cm}^{-3}\right)^{20}, \mathrm{Ni} / \mathrm{N}$-doped $\mathrm{C} / / \mathrm{Zn}$ battery $\left(0.66 \mathrm{mWh} \mathrm{cm} \mathrm{m}^{-3}, 0.13 \mathrm{~W} \mathrm{~cm}{ }^{-3}\right)^{45}, \mathrm{NiO} / / \mathrm{Fe}_{3} \mathrm{O}_{4}$ battery $\left(5.2 \mathrm{~mW} \mathrm{~h} \mathrm{~cm}^{-3}, 0.08 \mathrm{~W} \mathrm{~cm}^{-3}\right)^{21}, \mathrm{Ni} / \mathrm{Ni}(\mathrm{OH})_{2} / / \mathrm{Zn}$ battery $\left(2.9 \mathrm{~mW} \mathrm{~h} \mathrm{~cm}^{-3}, 0.14 \mathrm{~W} \mathrm{~cm}^{-3}\right)^{46}$. More encouragingly, our $\mathrm{NiCo} / /$ Sb battery also exhibits outstanding long-term cycling stability with a slight capacity fading ( 1.9\%) after 1000 cycles (Fig. $4 \mathrm{f})$, as well as a high CE (95.7\%). The charge/discharge profiles of the battery at the initial, middle and final stages remain almost the same in the voltage plateaus and charging/discharging times, again demonstrating its remarkable reversibility and stability.

\section{Discussion}

In summary, we demonstrated a highly reversible stripping/plating chemistry of $\mathrm{Sb}$ and thus provide a promising electrolytic metallic $\mathrm{Sb}$ anode for AABs. The diffusion behaviors of $\mathrm{SbO}_{2}-$ ions at the interface are effectively manipulated by an oxygen-rich functional interface, which could not only significantly promote the surface absorption of $\mathrm{SbO}_{2}{ }^{-}$in the Helmholtz layer to restrain the side reaction and increase the $\mathrm{CE}$; but also, lower the nucleation overpotential and induce the uniform Sb deposition. As a consequence, the Sb/FCS anode delivered an obviously improved durability with an excellent CE of more than $92.4 \%$ during the 1000 cycles, associated with a remarkable specific capacity of $627.1 \mathrm{~mA} \mathrm{~h} \mathrm{~g}^{-1}$ at $0.47 \mathrm{~mA} \mathrm{~h} \mathrm{~cm}^{-2}$ ( $95.0 \%$ DOD). Moreover, the as-prepared $\mathrm{NiCo} / / \mathrm{Sb} \mathrm{AAB}$ device delivered a prominent stability (98.1\% capacity retention after 1000 cycles), an outstanding maximum volumetric energy density $\left(8.2 \mathrm{~mW} \mathrm{~h} \mathrm{~cm}^{-3}\right)$ along with a peak power density $\left(0.4 \mathrm{~W} \mathrm{~cm}^{-3}\right)$, surpassing many of the stateof-the-art AABs reported recently. The development of the 
a
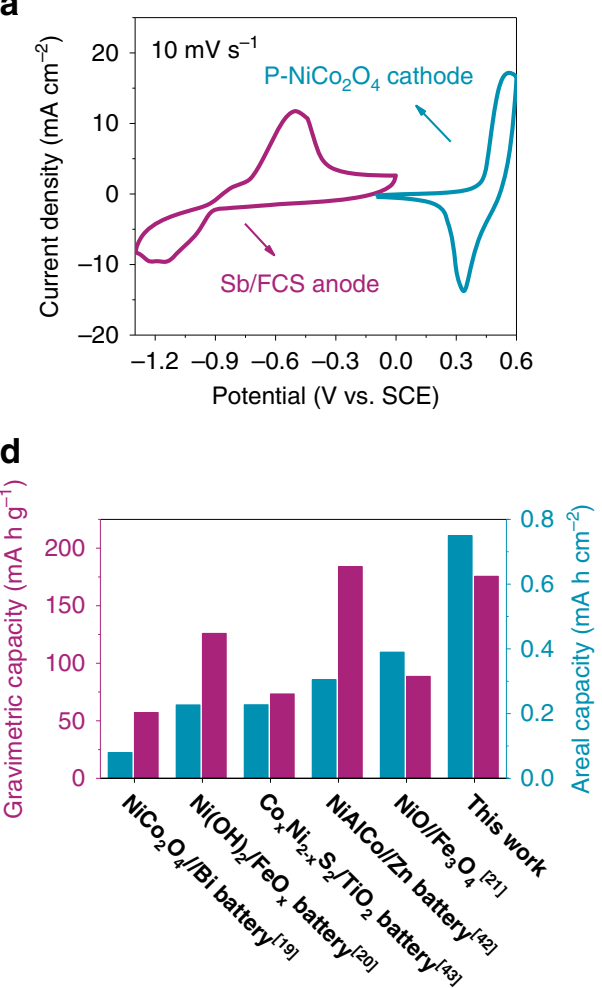

b

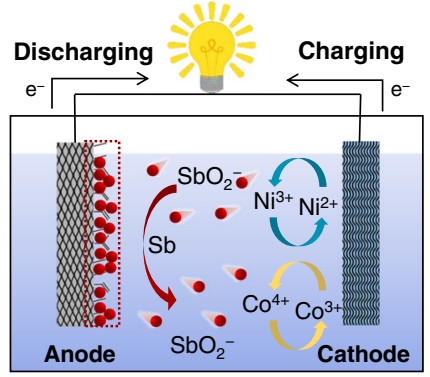

e

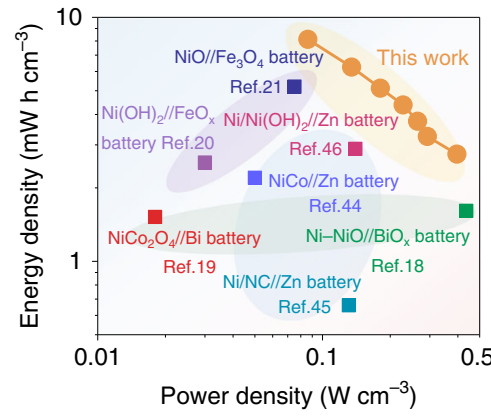

C

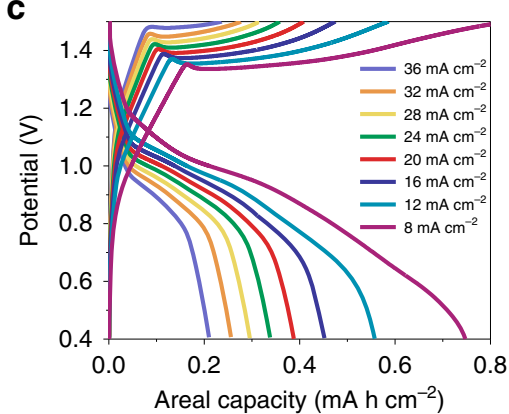

f

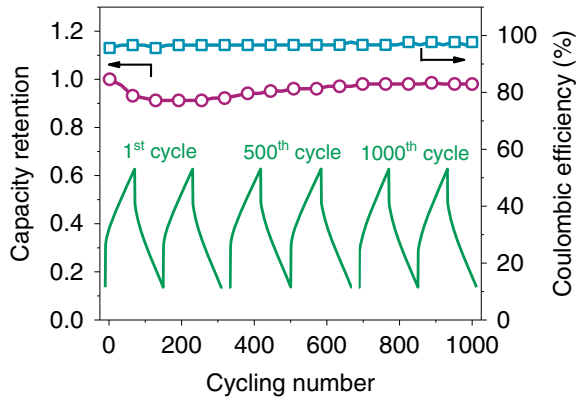

Fig. 4 Electrochemical performance of assembled $\mathbf{A A B}$ using Sb/FCS anode. a $\mathrm{CV}$ curves of the $\mathrm{P}-\mathrm{NiCO}_{2} \mathrm{O}_{4}$ cathode and $\mathrm{Sb} / \mathrm{FCS}$ anode measured at $10 \mathrm{mV} \mathrm{s}^{-1}$. b The energy storage mechanism of the NiCo//Sb battery. $\mathbf{c}$ Galvanostatic charge-discharge (GCD) curves at different current densities, $\mathbf{d}$ areal capacity and gravimetric capacity comparison with previous studies ${ }^{19-21,42,43}$, e Ragone plots, the values reported for other energy storage devices are added for comparison ${ }^{18-21,44-46}$ and $\mathbf{f}$ the cycling stability of the NiCo//Sb battery.

promising $\mathrm{Sb}$ anode in our work will be of immediate benefit to the exploration of high-performance AABs for practical utilization, particularly, for grid-scale energy storage.

\section{Methods}

Preparation of electrolyte. All reagents are of analytical grade and are directly used without any purification. $0.5 \mathrm{~g}$ of potassium antimony tartrate $\left(\mathrm{C}_{8} \mathrm{H}_{4} \mathrm{~K}_{2} \mathrm{O}_{12} \mathrm{Sb}_{2}\right)$ is dissolved in $30 \mathrm{ml} 1 \mathrm{M} \mathrm{KOH}$, resulting in a mixture of $1 \mathrm{M}$ $\mathrm{KOH}$ and $0.027 \mathrm{M} \mathrm{C}_{8} \mathrm{H}_{4} \mathrm{~K}_{2} \mathrm{O}_{12} \mathrm{Sb}_{2}$. The reaction equation for the formation of $\mathrm{SbO}_{2}{ }^{-}$is listed in Supplementary Note 2.

Preparation of CS and FCS electrodes. The CS substrate is purchased directly from Fuel Cell Earth, USA (plain carbon fiber cloth; $12.6 \mathrm{mg} \mathrm{cm}^{-2}$ ). Subsequently, the FCS substrate is obtained by CS after an electrochemical functional group introducing process. First, the CS is ultrasonic in water and ethanol for $10 \mathrm{~min}$ and undergoing controllable Ar plasma process by atomic layer deposition (ALD) technology (ALD-SC6-PE, Syskey Technology Co., Ltd.) to produce clean surface. The electrochemical functional group introducing is then carried out through a standard three-electrode system in a solution composed by $\mathrm{H}_{2} \mathrm{SO}_{4}(98 \%)$ and $\mathrm{HNO}_{3}(68 \%)$ with a volume ratio of $1: 1$. The system uses Pt electrode as the counter electrode, saturated calomel electrode (SCE) as the reference electrode and $\mathrm{CS}$ as the working electrode. The electrochemical functional group introducing process is conducted with a constant voltage of $3 \mathrm{~V}$ for $15 \mathrm{~min}$ at the room temperature. The FCS is washed with deionized water after the process and dried in the oven at $60^{\circ} \mathrm{C}$ for $3 \mathrm{~h}$.

Preparation of $\mathbf{P}-\mathrm{NiCO}_{2} \mathrm{O}_{\mathbf{4}}$ cathode. $\mathrm{P}-\mathrm{NiCO}_{2} \mathrm{O}_{4}$ is obtained by a previously reported hydrothermal and annealing method growing on nickel foam. Initially, urea $(15 \mathrm{mmol}), \mathrm{NiCl}_{2} \cdot 6 \mathrm{H}_{2} \mathrm{O}(5 \mathrm{mmol})$, and $\mathrm{CoCl}_{2} \cdot 6 \mathrm{H}_{2} \mathrm{O}(10 \mathrm{mmol})$ are dissolved in $75 \mathrm{ml}$ deionized water under vigorous magnetic stirring. After the mixture is clarified, $35 \mathrm{ml}$ solution is added into a $50 \mathrm{ml}$ Teflon-lined stainless steel autoclave with a piece of cleaned nickel foam $(2.7 \mathrm{~cm} \times 4 \mathrm{~cm})$. The autoclave is heated at $120^{\circ} \mathrm{C}$ for $6 \mathrm{~h}$ and then cooled down to room temperature. After washed with deionized water and dried at $70{ }^{\circ} \mathrm{C}$ in air, the prepared $\mathrm{NiCo}_{2} \mathrm{O}_{4}$ is calcined at $300^{\circ} \mathrm{C}$ for $2 \mathrm{~h}$ and the heating rate was $2{ }^{\circ} \mathrm{C} \mathrm{min}-1$. To get $\mathrm{P}-\mathrm{NiCo}_{2} \mathrm{O}_{4}$, the obtained samples are annealed at $250^{\circ} \mathrm{C}$ for
$60 \mathrm{~min}$ in $\mathrm{Ar}$ atmosphere in the presence of $\mathrm{NaH}_{2} \mathrm{PO}_{2} \cdot \mathrm{H}_{2} \mathrm{O}(1.2 \mathrm{~g})$. The mass loading of the $\mathrm{P}-\mathrm{NiCO}_{2} \mathrm{O}_{4}$ is $3.1 \mathrm{mg} \mathrm{cm}^{-2}$ (BT25S, $0.01 \mathrm{mg}$ ), and the thickness of the cathode after tableting is $0.04 \mathrm{~cm}$.

Electrochemical measurements. Galvanostatic charge/discharge curves (GCD) and cyclic voltammogram $(\mathrm{CV})$ are recorded using Neware battery system (CT3008-5V10mA-164, Shenzhen, China) and electrochemical work-station (CHI 760E). The Princeton electrochemical workstation (PARSTAT MC) was used to collect Electrochemical impedance spectroscopy (EIS). All electrochemical characterization is performed at room temperature. For Sb plating/stripping test, CS and FCS substrates are used as working electrode with a surface area of $0.5 \mathrm{~cm}^{2}$, graphite rod was employed as counter electrode, and SCE as the reference electrode in three-electrode system. The electrolyte is a mixed solution of $1 \mathrm{M} \mathrm{KOH}$ and $0.027 \mathrm{M} \mathrm{C}_{8} \mathrm{H}_{4} \mathrm{~K}_{2} \mathrm{O}_{12} \mathrm{Sb}_{2}$. The charging process is achieved by a galvanostatic charging method to charge a fixed value $\left(0.47 \mathrm{~mA} \mathrm{~h} \mathrm{~cm}^{-2}\right)$ and the discharging process is achieved by a galvanostatic discharging method to discharge to $0 \mathrm{~V}$. The mass loadings of $\mathrm{Sb} / \mathrm{CS}$ and $\mathrm{Sb} / \mathrm{FCS}$ deposition electrodes are $0.64 \mathrm{mg} \mathrm{cm}^{-2}$ and $0.71 \mathrm{mg} \mathrm{cm}^{-2}$, respectively while charging $0.47 \mathrm{~mA} \mathrm{~h} \mathrm{~cm}^{-2}$ (BT25S, $0.01 \mathrm{mg}$ ). The aqueous $\mathrm{NiCo} / / \mathrm{Sb}$ battery is tested in two-electrode system with the same electrolyte, using $\mathrm{P}-\mathrm{NiCo}_{2} \mathrm{O}_{4}$ as cathode and FCS substrate as anode. The mass loading of $\mathrm{Sb} / \mathrm{FCS}$ electrode at $8 \mathrm{~mA} \mathrm{~cm}^{-2}$ is $1.1 \mathrm{mg} \mathrm{cm}^{-2}$. Calculations about capacity, energy density and power density of $\mathrm{Sb}$ anode and $\mathrm{NiCo} / / \mathrm{Sb}$ battery are shown in Supplementary Note 3 .

Material characterization. Field-emission SEM (SEM, JSM-6330F and SEM, g500) and TEM (FEI Tecnai $\mathrm{G}^{2}$ F30) are used to character the morphology and the microstructure of the deposited Sb on the substrate. XRD (D-MAX 2200 VPC, RIGAKU), XPS (NEXSA, Thermo FS) are used to character the crystal phase and composition of the deposited $\mathrm{Sb}$ on the substrate.

Computational details. All the calculations were performed using the Vienna Abinitio Simulation Package (VASP). The generalized gradient approximation (GGA) in the scheme of Perdew-Burke-Ernzerhof (PBE) function was used to calculate the electron exchange-correlation interactions. The cutoff energy for plane-wave basis set was set to $400 \mathrm{eV}$. All atomic positions and lattice vectors were fully optimized using a conjugate gradient algorithm to obtain the unstrained 
configuration. Atomic relaxation was performed until the change of total energy was less than $1 \times 10^{-5} \mathrm{eV}$, all the forces on each atom were smaller than $0.01 \mathrm{eV} / \AA$. The adsorbed surface was used (002) slab with $12 \AA$ vacuum in the c-direction to eliminate periodic boundary interaction. Monkhorst-Pack scheme K-point grid was set to $3 \times 3 \times 1$ during surface relaxation.

\section{Data availability}

The data that support the findings of this study are available from the corresponding authors upon reasonable request.

Received: 3 July 2020; Accepted: 11 November 2020;

Published online: 04 January 2021

\section{References}

1. Li, Y. et al. Growth of conformal graphene cages on micrometre-sized silicon particles as stable battery anodes. Nat. Energy 1, 1-8 (2016).

2. Li, Z. et al. A sulfur host based on titanium monoxide@carbon hollow spheres for advanced lithium-sulfur batteries. Nat. Commun. 7, 13065 (2016).

3. Wan, F. \& Niu, Z. Design strategies for vanadium-based aqueous zinc-ion batteries. Angew. Chem. Int. Ed. 58, 16358-16367 (2019).

4. Suo, L. et al. "Water-in-salt" electrolyte enables high-voltage aqueous lithiumion chemistries. Science 350, 938-943 (2015).

5. Zhang, $\mathrm{H}$. et al. Boosting $\mathrm{Zn}$-ion energy storage capability of hierarchically porous carbon by promoting chemical adsorption. Adv. Mater. 31, 1904948 (2019).

6. Chao, D. et al. An electrolytic $\mathrm{Zn}-\mathrm{MnO}_{2}$ battery for high-voltage and scalable energy storage. Angew. Chem. Int. Ed. 58, 7823-7828 (2019).

7. Zhong, C. et al. Decoupling electrolytes towards stable and high-energy rechargeable aqueous zinc-manganese dioxide batteries. Nat. Energy $\mathbf{5}$, 440-449 (2020).

8. Hong, J. J. et al. A dual plating battery with the Iodine/[ $\left[\mathrm{ZnI}_{\mathrm{x}}\left(\mathrm{OH}_{2}\right)_{4-\mathrm{x}}\right]_{2-\mathrm{x}}$ cathode. Angew. Chem. Int. Ed. 131, 2-8 (2019).

9. Zhang, Y. et al. Multiscale graphene-based materials for applications in sodium ion batteries. Adv. Energy Mater. 9, 1803342 (2019).

10. Zeng, Y. et al. An ultrastable and high-performance flexible fiber-shaped Ni$\mathrm{Zn}$ battery based on a Ni-NiO heterostructured nanosheet cathode. Adv. Mater. 29, 1702698 (2017).

11. Parker, J. F. et al. Rechargeable nickel-3D zinc batteries: an energy-dense, safer alternative to lithium-ion. Science 356, 415-418 (2017).

12. Zhang, X. et al. Oxygen defect modulated titanium niobium oxide on graphene arrays: an open-door for high-performance $1.4 \mathrm{~V}$ symmetric supercapacitor in acidic aqueous electrolyte. Adv. Funct. Mater. 28, 1805618 (2018).

13. Wang, M. et al. Making fiber-shaped Ni//Bi battery simultaneously with high energy density, power density, and safety. Adv. Funct. Mater. 30, 1905971 (2019).

14. Liu, J. et al. A flexible quasi-solid-state nickel-zinc battery with high energy and power densities based on 3D electrode design. Adv. Mater. 28, 8732-8739 (2016).

15. Li, M. et al. Finely crafted 3D electrodes for dendrite-free and highperformance flexible fiber-shaped Zn-Co batteries. Adv. Funct. Mater. 28, 1802016 (2018).

16. Ma, L. et al. Initiating a mild aqueous electrolyte $\mathrm{Co}_{3} \mathrm{O}_{4} / \mathrm{Zn}$ battery with $2.2 \mathrm{~V}$ high voltage and 5000-cycle lifespan by a $\mathrm{Co}(\mathrm{III})$ rich-electrode. Energy Environ. Sci. 11, 2521-2530 (2018).

17. García-Plaza, M., Serrano-Jiménez, D., Eloy-García Carrasco, J. \& AlonsoMartínez, J. A Ni-Cd battery model considering state of charge and hysteresis effects. J. Power Sources 275, 595-604 (2015).

18. Zeng, Y. et al. Engineering high reversibility and fast kinetics of Bi nanoflakes by surface modulation for ultrastable nickel-bismuth batteries. Chem. Sci. 10, 3602-3607 (2019).

19. Zeng, Y. et al. Flexible ultrafast aqueous rechargeable $\mathrm{Ni} / / \mathrm{Bi}$ battery based on highly durable single-crystalline bismuth nanostructured anode. Adv. Mater. 28, 9188-9195 (2016).

20. Wang, H. et al. An ultrafast nickel-iron battery from strongly coupled inorganic nanoparticle/nanocarbon hybrid materials. Nat. Commun. 3, 917 (2012).

21. Guan, C. et al. High-performance flexible solid-state Ni/Fe battery consisting of metal oxides coated carbon cloth/carbon nanofiber electrodes. Adv. Energy Mater. 6, 1601034 (2016).

22. Zeng, Y. et al. Oxygen-vacancy and surface modulation of ultrathin nickel cobaltite nanosheets as a high-energy cathode for advanced $\mathrm{Zn}$-ion batteries. Adv. Mater. 30, 1802396 (2018).
23. Yan, Z., Wang, E., Jiang, L. \& Sun, G. Superior cycling stability and high rate capability of three-dimensional $\mathrm{Zn} / \mathrm{Cu}$ foam electrodes for zinc-based alkaline batteries. RSC Adv. 5, 83781-83787 (2015).

24. Huang, J. et al. Polyaniline-intercalated manganese dioxide nanolayers as a high-performance cathode material for an aqueous zinc-ion battery. Nat. Commun. 9, 2906 (2018).

25. Zeng, Y. et al. In situ activation of 3D porous Bi/carbon architectures: toward high-energy and stable nickel-bismuth batteries. Adv. Mater. 30, 1707290 (2018).

26. Li, X., Sun, M., Ni, J. \& Li, L. Template-free construction of self-supported Sb prisms with stable sodium storage. Adv. Energy Mater. 9, 1901096 (2019)

27. Han, Y. et al. Stabilizing antimony nanocrystals within ultrathin carbon nanosheets for high-performance K-ion storage. Energy Storage Mater. 20, 46-54 (2019).

28. Ulrich, N. Speciation of antimony(III), antimony(V) and trimethylstiboxide by ion chromatography with inductively coupled plasma atomic emission spectrometric and mass spectrometric detection. Anal. Chim. Acta 359, 245-253 (1998).

29. Wikstrom, L. L. \& Nobe, K. Electrode kinetics of antimony in alkaline solutions. J. Appl. Electrochem. 14, 257-263 (1984).

30. Vink, B. W. Stability relations of antimony and arsenic compounds in the light of revised and extended Eh-pH diagrams. Chem. Geol. 130, 21-30 (1996).

31. Wang, Q. \& Wang, Y. Fundamental electrochemical behavior of antimony in alkaline solution. J. Sustain. Metall. 5, 606-616 (2019).

32. Wang, W. et al. A novel exfoliation strategy to significantly boost the energy storage capability of commercial carbon cloth. Adv. Mater. 27, 3572-3578 (2015).

33. Wang, G. et al. Solid-state supercapacitor based on activated carbon cloths exhibits excellent rate capability. Adv. Mater. 26, 2676-2682 (2014).

34. Zhang, N. et al. Spherical nano-Sb@C composite as a high-rate and ultrastable anode material for sodium-ion batteries. Nano Res. 8, 3384-3393 (2015).

35. Luo, W. et al. Bottom-up confined synthesis of nanorod-in-nanotube structured Sb@N-C for durable lithium and sodium storage. Adv. Energy Mater. 8, 1703237 (2018).

36. Zhu, J. et al. Controlled synthesis of Sb nanostructures and their conversion to $\mathrm{CoSb}_{3}$ nanoparticle chains for Li-ion battery electrodes. Chem. Mater. 22, 5333-5339 (2010).

37. Zeng, Y. et al. Dendrite-free zinc deposition induced by multifunctional CNT frameworks for stable flexible $\mathrm{Zn}$-ion batteries. Adv. Mater. 31, 1903675 (2019).

38. Fei, J. et al. A flexible $\mathrm{Sb}_{2} \mathrm{O}_{3} /$ carbon cloth composite as a free-standing high performance anode for sodium ion batteries. Chem. Commun. 53, 13165-13167 (2017).

39. Xie, X. et al. Manipulating the ion-transfer kinetics and interface stability for high-performance zinc metal anodes. Energy Environ. Sci. 13, 503-510 (2020)

40. Qiu, W., Xiao, H., Yu, M., Li, Y. \& Lu, X. Surface modulation of $\mathrm{NiCo}_{2} \mathrm{O}_{4}$ nanowire arrays with significantly enhanced reactivity for ultrahigh-energy supercapacitors. Chem. Eng. J. 352, 996-1003 (2018).

41. Pješčić, M. G., Šušić, M. V. \& Minić, D. Reduction of Sb(III) on the mercury electrode. Electroanal. Chem. Interfacial Chem. 57, 429-432 (1974).

42. Gong, M. et al. Ultrafast high-capacity NiZn battery with NiAlCo-layered double hydroxide. Energy Environ. Sci. 7, 2025 (2014).

43. Liu, J. et al. Aqueous rechargeable alkaline $\mathrm{Co}_{\mathrm{x}} \mathrm{Ni}_{2-\mathrm{x}} \mathrm{S}_{2} / \mathrm{TiO}_{2}$ battery. ACS Nano 10, 1007-1016 (2016).

44. Huang, Y. et al. Weavable, conductive yarn-based $\mathrm{NiCo} / / \mathrm{Zn}$ textile battery with high energy density and rate capability. ACS Nano 11, 8953-8961 (2017).

45. Meng, L. et al. Electrochemically activated nickel-carbon composite as ultrastable cathodes for rechargeable nickel-zinc batteries. ACS Appl. Mater. Interfaces 11, 14854-14861 (2019).

46. Cheng, X. et al. Facile activation of commercial Ni foil as robust cathode for advanced rechargeable Ni-Zn battery. Electrochim. Acta 263, 311-317 (2018).

\section{Acknowledgements}

We thank the financial support by the National Natural Science Foundation of China (21822509, U1810110, and 21802173), Science and Technology Planning Project of Guangdong Province (2018A050506028), and Natural Science Foundation of Guangdong Province (2018A030310301). The calculation of this work was performed on TianHe-2, thanks for the support of National Supercomputing Center in Guangzhou (NSCC-GZ). The authors also thank the Photoemission Endstations (BL10B) in National Synchrotron Radiation Laboratory (NSRL) for help in characterizations.

\section{Author contributions}

X.Lu and H.Z. planned and designed the project. H.Z. and Q.L. fabricated the materials and performed the electrochemical experiments. D.Z. performed and analyzed the XPS result. 
F.Y. conducted the DFT analysis. X.Lu, H.Z., Q.L., and X.Liu analyzed the data and wrote the manuscript. All authors discussed the results and commented on the manuscript.

\section{Competing interests}

The authors declare no competing interests.

\section{Additional information}

Supplementary information is available for this paper at https://doi.org/10.1038/s41467020-20170-8

Correspondence and requests for materials should be addressed to X.L.

Peer review information Nature Communications thanks the anonymous reviewer(s) for their contribution to the peer review of this work. Peer reviewer reports are available.

Reprints and permission information is available at http://www.nature.com/reprints
Publisher's note Springer Nature remains neutral with regard to jurisdictional claims in published maps and institutional affiliations.

\begin{abstract}
bution 4.0 International License, which permits use, sharing, adaptation, distribution and reproduction in any medium or format, as long as you give appropriate credit to the original author(s) and the source, provide a link to the Creative Commons license, and indicate if changes were made. The images or other third party material in this article are included in the article's Creative Commons license, unless indicated otherwise in a credit line to the material. If material is not included in the article's Creative Commons license and your intended use is not permitted by statutory regulation or exceeds the permitted use, you will need to obtain permission directly from the copyright holder. To view a copy of this license, visit http://creativecommons.org/licenses/by/4.0/.
\end{abstract}

